\title{
Article
}

\section{CONTEXTUAL CONSTRAINTS AND THE RELEVANCE DISCOVERY PROCESS: CHALLENGES FACING KNOWLEDGE GATEKEEPERS IN EMERGING ECONOMIES}

\author{
Kuznetsov, Andrei and Kuznetsova, Olga \\ Available at http://clok.uclan.ac.uk/15792/ \\ Kuznetsov, Andrei ORCID: 0000-0003-4539-0711 and Kuznetsova, Olga (2016) \\ CONTEXTUAL CONSTRAINTS AND THE RELEVANCE DISCOVERY PROCESS: \\ CHALLENGES FACING KNOWLEDGE GATEKEEPERS IN EMERGING ECONOMIES. \\ International Social Science Journal . ISSN 0020-8701
}

It is advisable to refer to the publisher's version if you intend to cite from the work. http://dx.doi.org/10.1111/issj.12086

For more information about UCLan's research in this area go to http://www.uclan.ac.uk/researchgroups/ and search for < name of research Group>.

For information about Research generally at UCLan please go to http://www.uclan.ac.uk/research/

All outputs in CLoK are protected by Intellectual Property Rights law, including Copyright law. Copyright, IPR and Moral Rights for the works on this site are retained by the individual authors and/or other copyright owners. Terms and conditions for use of this material are defined in the policies page.

\section{CLoK}

Central Lancashire online Knowledge www.clok.uclan.ac.uk

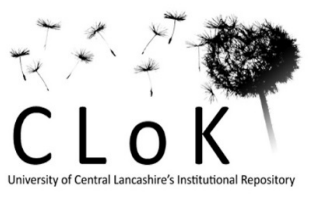


CONTEXTUAL CONSTRAINTS AND THE RELEVANCE DISCOVERY

PROCESS:

CHALLENGES FACING KNOWLEDGE GATEKEEPERS IN EMERGING

ECONOMIES

\title{
A.Kuznetsov \& O.Kuznetsova \\ Paper accepted for publication in International Social Science Journal
}

\begin{abstract}
:
The paper explores conceptually the process of relevance discovery prompted by a major alteration in the institutional settings that have caused a radical change in the existing management knowledge paradigm as new mostly "imported" knowledge replaces the "old" knowledge base. This situation puts significant pressure on a particular group of experts designated in the literature as "knowledge gatekeepers". Their role is particularly important when external information requires contextual interpretation in order to be considered useful by other members of the social group. The paper focuses on recontextualisation as a critical element of relevance discovery and the transformation of "imported" knowledge from irrelevant to relevant and analyses the factors that influence the ability of knowledge gatekeepers to cope with the task of contextualisation. An account of two field studies of post-communist marketisation is used to illustrate the challenges of contextualisation.
\end{abstract}

\section{Keywords:}

relevance discovery, knowledge gatekeepers, contextualisation, knowledge relevance, institutional shift, business and management education, post-communist transformation. 


\section{CONTEXTUAL CONSTRAINTS AND THE RELEVANCE DISCOVERY \\ PROCESS: CHALLENGES FACING KNOWLEDGE GATEKEEPERS IN \\ EMERGING ECONOMIES}

\section{Introduction: research justification and problem statement}

Knowledge transfer has evolved as an important theme in organisational literature (Argote \& Ingram 2000; Chang et al. 2012; Phelps et al. 2012). Nonetheless, there are still aspects of this phenomenon that remain underresearched. One of them is how the process of discovery of relevance of incoming knowledge affects knowledge transfer. Only few papers address this issue directly (Schulz 2001; Schulz 2003; Yang et al. 2008). They are based mostly on the examination of knowledge flows between units in multinational corporations where knowledge transfer tends to be a monitored and managed process that deliberately targets performance enhancement (Asmussen et al. 2013). Even when in the receiving units the relevance of new knowledge is not taken for granted, uncertainty over relevance is not seen by researchers as a major obstacle to knowledge absorption. On the contrary, uncertain relevance is treated as something that makes new knowledge “interesting” and "alluring" (Schulz 2001). Although not presented as an entirely conflictfree, the relevance discovery process is generally described as a positive experience because the assimilation of new knowledge is made easier by similarities and overlaps in the knowledge trajectories that exist in different units of the same organisation. A knowledge trajectory is conceptualized as a continuous and incremental accumulation of knowledge within the organisation (Pandza \& Thorpe 2009). Adaptation of new exogenous knowledge discontinues the existing trajectory and starts a new one, but in most cases, the 
organizational literature argues, it is a routine rather than an extraordinary event because new and old knowledge tend to be complementary.

But what if new and old knowledge do not agree? How is the relevance of new knowledge established? The literature typically assumes that in an organisation the need to ascertain relevance does not happen very often because knowledge normally flows to places for which it is deemed relevant (Schulz 2003). The catastrophic discontinuation of a knowledge trajectory following a conflict of new and old knowledge may be indeed rare, but this does not make it less intriguing or less consequential because such an event is likely to be a cause of severe and enduring problems with adoption and absorption of new knowledge. In fact, a sudden disruption of the knowledge trajectory is likely to become more common as modern businesses are increasingly exposed to rapid and often startling breakthroughs in technology, communications, materials, etc., on the one hand, and to equally dramatic changes in social conditions and business practices, on the other. In the recent past, to give just one example, these latter were represented by the emergence of a powerful social consensus built around the ideas of sustainability, circular economy, corporate citizenship, etc. The impact of these factors is reinforced further by the consequences of globalisation that increases the pool of potentially relatable knowledge thus pushing the issue of relevance recognition firmly to the front.

In this paper we discuss the consequences of a situation in which discontinuities in knowledge trajectories make new knowledge available that has uncertain relevance. This necessarily triggers a relevance discovery processes that relies on the skills of a particular 
group of experts whom, following Allen (1977) and Tushman and Katz (1980), we call "knowledge gatekeepers". They contribute to relevance discovery through contextualization. However, relevance is easily biased and contextualisation is never a straightforward task, and this poses challenges for knowledge gatekeepers and gatekeeping. We investigate the challenges of the relevance discovery process that are associated with the recontextualisation of "new" knowledge that becomes available through international transfer. We frame our study as a case in demonstrating that knowledge is always socially embedded and context dependent, and more so in technologies of governance such as management theories.

Relevance is a measure of how new knowledge is connected or applicable to a given matter. Greater relevance makes it easier for the knowledge recipient to derive benefits from it, increasing the value of such knowledge and making one more willing to seek it out. The originality of our approach is that we investigate the process of relevance discovery in a situation in which knowledge transfer is accompanied with a dramatic non-trivial discontinuity in the existing knowledge trajectory, thus making the relevance discovery process particularly problematic. Lancaster (1971) introduced the notion of revealed relevance. According to Lancaster, something has revealed relevance if this something causes people to react. When applied to knowledge, revealed relevance analysis suggests that some elements of available knowledge may be widely recognised as relevant, whilst the relevance of others may not be instantly apparent, causing people to ignore them. With time, however, the situation may change and members of society may start to engage with previously ignored elements of knowledge. Significantly, transition to revealed relevance 
does not require changes in the substance of knowledge as such, but is caused by a change in perception held by the users of knowledge following the expansion of their horizons of cognition based on increment in skills, intellectual capital and experience.

A critical role in forming such perception belongs to selected individuals or groups thereof who are qualified to make a judgement about the relevance of knowledge. Writing about innovation in organisation, Allen (1977, p. 145) characterised them as knowledge gatekeepers, "a small number of key people to whom others frequently turned for information. These key people differ from their colleagues in the degree to which they expose themselves to sources of technological information outside their organisation". Since the publication of Allen's work, the notion of knowledge gatekeeping has been extended in the literature to a wide range of knowledge exchanges occurring in organisations, networks and social groups (see for example Harorimana 2008; Herzog 1981; MacDonald and Williams 1993; Morrison 2004; Tushman and Katz 1980; Vinding 2006).

Gatekeepers are of particular importance when the external information requires contextual interpretation to be considered useful by other members of the organisation (Lewin et al. 2011), thus transforming potential relevance into relevance revealed. When implementing recontextualisation knowledge gatekeepers unavoidably rely on own experience and expertise, which means that new knowledge acquires relevance by being exposed to and recombined with old knowledge (Schulz 2001: p.664). The novel aspect of the investigation undertaken in this paper is that we explore conceptually the implications of a 
situation, in which knowledge gatekeepers face the necessity to adjust to a radical change in the knowledge paradigm caused by a major institutional shift. As a result, they have to cope with an acute conflict between new ideas brought about by this shift and own convictions entrenched in the outgoing institutional settings. Our aim is to examine how the challenges associated with adapting to the new institutional environment impede the transformation of available knowledge from irrelevant to relevant as knowledge gatekeepers wrestle with contextualising new knowledge.

In this paper, we use a specific group of knowledge gatekeepers - academics in the domain of business and management working in the university sector in emerging market economies. There are two reasons for this choice. The first relates to the position occupied by academics in the knowledge production chain. As professional knowledge workers, they partake in the production, evaluation and dissemination of knowledge and are involved therefore, both in the supply and demand side of knowledge creation. This makes the academic a key figure in the process of legitimising new knowledge and establishing its relevance. The second reason is that in the not so distant past a substantial group of scholars found themselves facing a critical shift in knowledge paradigm caused by a non-trivial discontinuation of the knowledge trajectory, thus providing this study with a vivid illustration of its main conceptual points.

The group we examined consists of university tutors operating in the post-communist emerging markets. Under central planning the theory and reality of management contrasted sharply with what was the norm in the market economies ${ }^{1}$. In fact, there was no place for 
economic management or strategic management at the enterprise level although enterprises had their own managerial teams (Kuznetsov \& Kuznetsova 1996). By comparison with firms operating in a market economy, under central planning in terms of managerial functions enterprises were less complex, less diversified and less self-sufficient as far as rights and responsibilities were concerned. Conceptually, they were conceived as basic units for converting inputs into outputs according to plans and targets set by the omnipotent state. As a result, their rights and responsibility were severely restricted. Managers did not have to make decisions on prices, the product mix, resource allocation and other standard economic variables. Instead, they were expected to concentrate on production and the implementation of directives designed by ministries and planning authorities who monopolised strategic decision-making. The business macro-environment was fundamentally different too. One of its foremost features was the presence of the so-called soft budget constraints, making the risk of bankruptcy as well as many financial restrictions either non-existent or irrelevant (Kornai 1980). At the same time many enterprises enjoyed the position of technological monopoly which allowed them to pursue the policy of rentseeking and lead to a successful struggle with central economic authorities to scale down plan orders for output while securing an increase in the allocation of labour input and materials. Managers had never been trained, or paid, to design business strategy, and their customary behaviour was characterised by tactical responses and opportunism.

During post-communist transition, after decades of suppression of market exchange and ideology, local academics confronted the challenge of making sense and adapting for internal consumption (reconceptualising) a stream of radically new and, importantly, non- 
contextualised (in historical terms) ideas in the field of economics, business and management. We demonstrate that the relevance discovery process of new management knowledge was significantly affected by problems that the knowledge gatekeepers had with reconciling this knowledge with the objective reality and entrenched theoretical beliefs.

Although we concentrate on actors operating within the university sector, the findings have wider practical implications as on many occasions, and in particular in cross-border settings, managerial roles may incorporate activities related to knowledge gatekeeping. This makes our investigation relevant not only to academics interested in organisational studies and knowledge management, but also to practitioners dealing with the challenges of cross-border knowledge transfer.

We use an inductive approach and predominantly engage in an interpretive ethnographic investigation. Its advantage is that it is not limited to one fact gathering procedure. Instead, it encompasses a range of data generation techniques that produce accounts of research based on participants' experiences of events and phenomena in their natural setting including, importantly, the researcher's own experience (Wilkinson 2012). Accordingly, our investigation relies on participant observation and a variety of archival materials of own research, such as interview notes and survey results, that we have collected during 
almost ten years of participation in technical assistance programmes for universities in the post-Soviet states.

\section{Relevance and context: setting the scene}

When institutions crumble

During knowledge transfer, gatekeepers serve as the interface between the recipients of knowledge and the environment in which the knowledge was originally produced (Lewin et al. 2011). This environment is the context in which the transferred knowledge is originally embedded. Context is critical for our ability to comprehend because it is the sum of the characteristics of the world that give clues to our perceptions. For many years management scholarship was shaped by studies conducted in developed capitalist economies that shared many similarities in the way in which the market mechanism was performing. This allowed some authors to argue that management knowledge was essentially context-free (Blair \& Hunt 1986). The emergence in the world arena of a cohort of transition economies ${ }^{2}$, in which the market mechanism and the accompanying social structures are in the process of establishing themselves, has made it necessary to revise this view. Numerous studies report that often the findings from research based on Western experience does not replicate in other nations (Tsui 2004), highlighting the fact that management knowledge is strongly influenced by the particular circumstances under which it is produced, is context-embedded. To reflect this, Child (2000) proposed to distinguish between "high-context" and "low-context" theorizing, with the former stressing national differences and the latter emphasizing universal applicability in models and constructs. Child further argued that the low-context perspective refers primarily to the values and 
norms expressed and reproduced through the medium of social institutions and are ideational in character (Child 2000: p.40).

The classification proposed by Child emphasises the role of institutional commonality as a prerequisite for the generalisation of management theories. However, this condition does not always hold. The diverse and populous group of economies with emerging markets is a case in hand: one characteristic that these otherwise very different economies share is exactly the ongoing process of profound institutional transformations and the consequent radical alteration of business conditions (Vercueil 2012). These countries are going through the phase during which the remnants of pre-market institutions, in particular in the form of ideologies, beliefs, cultural values, etc., are still present, competing for influence on decision making with the values and norms driven by market institutions. This complex and fluid situation is a fertile ground for investigating how the relevance of management knowledge and the relationship between theory and practice are ascertained.

In this paper we restrict our focus to the national system of business tertiary education as an entry point for management knowledge under the condition of post-communist marketisation. What makes this choice interesting and significant from the point of view of the study of the relevance discovery process is that in these countries academics, in their role of the gatekeepers of management knowledge, had to go through a period of extreme stress and uncertainty caused by fundamental institutional changes. They faced the challenge of bridging a profound gap in ideology, theory and practice of management that had existed between their countries and the developed market economies for many decades. 
They had to deal with the influx of the off-the-shelf knowledge imported wholesale from countries with a patently different historical and social background. The literature argues that experts are able to revise their cognitive patterns quite flexibly in response to changes in environmental cues as long as they are able to rely upon an amassed "repertoire of complex cognitive maps to reframe problems and to discriminate from one pattern into another" (Raelin 2009: p.502). Our attention, however, is drawn to a situation in which the repertoire in question suffices no longer. During the earlier stages of reforms, the influx of modern Western management theory coincided with the period of a dramatic shift in the institutional environment. This created a contextual near vacuum at the moment when the task of evaluating the relevance of incoming knowledge acquired great significance.

There is a body of literature that concentrates on differences in culture, attitudes and behaviours as factors that obstructed the early recognition of Western management knowledge as relevant in the transition economies (McCarthy \& Puffer 2003; May et al. 2005; Michailova \& Husted 2003). Although this approach has its merits, it is our contention that a major obstacle in the way of discovering the relevance of imported knowledge was that even theorizing that normally falls within the low-context category had to be the subject of substantial recontextualisation to better agree with the new socioeconomic situation in the country.

\section{Contextualisation: paving way for knowledge adoption}

In the literature the term knowledge has many interpretations. Our choice is determined by our objective. Following Schulz (2001), in our analysis knowledge is what has been learned 
from experience or study. What follows from this definition is that knowledge has a strong link with the context in which it is acquired. This link is explicit when knowledge is gained through experience. But even when obtained through study, knowledge involves some degree of contextualisation. It is because knowledge requires more than blind belief. In Theory of Knowledge philosopher Keith Lehrer argues that knowledge has as its requisite a special kind of belief, which is acceptance based on truth: "A person need not have a strong feeling that something is true in order to know that it is. What is required is acceptance of the appropriate kind, acceptance in the interest of obtaining a truth and avoiding an error in what one accepts" (Lehrer 1990: p.11). Such acceptance, Lehrer continues, is complete if new knowledge is coherent with a system of things a person accepts. In the same vein, the management literature emphasises the importance of aligning new knowledge with the experience of the users of knowledge to give it credibility (Booker et al. 2008). To get ground, new ideas cannot depart entirely from the existing general body of knowledge. Cohen and Levinthal (1994) talk about the "path dependence" of knowledge absorption, pointing at the existing level of prior related knowledge as an essential determinant of the absorptive capacity. Developing this argument further, Guilhon (2001) emphasises the centrality of reconceptualisation as an element of knowledge transfer that serves to shorten the cognitive distance between knowledge donors and knowledge endusers by positioning incoming knowledge within a cognitive frame that is familiar to the latter.

What follows from this analysis is that for knowledge gatekeepers the relevance discovery process is to a great degree the act of contextualisation that gives knowledge credibility 
and acceptance. Contextualisation is crucially important for securing relevance, in particular when management knowledge travels between mismatched institutional settings. The authenticity of even the low-context knowledge, when adapted for local appropriation, depends on the qualitative characteristics of the communication process and the attitude of the gatekeepers towards the knowledge they “dispense". In emerging markets, fundamental changes in the economic mechanism, political system and social values have made redundant and unusable much of the indigenous scholarship. In this situation, educationists were forced to count heavily on Western narrative in the form of texts and other teaching materials. These materials alone, however, could not create the density of shared experience sufficient to allow competent evaluation of the relevance and applicability of the transposed knowledge, considering that the personal experience of the market economy of the educational professionals was as recent as that of their co-citizens.

Under these circumstances, we argue, the demarcation line between the transfer of knowledge and creation of new knowledge becomes blurred. The local academics are required, using texts and methods originally developed within a very different set of historical, intellectual and social references, to set up a decoding framework and a cognitive environment that would allow their audience to transform information into knowledge. The perceived relevance of the incoming knowledge depends, therefore, on the ability of the academics to contextualise (adapt to a given context) by referencing it to a complex "web" of other socially embedded ideas. Their attitude and dexterity, however, cannot be taken for granted. The subject matter, business knowledge, only adds to the pressure, being an elaborate mesh of interconnected concepts not liable to be readily comprehended 
independently of one another or out of context. The activities of the knowledge gatekeepers can add value to knowledge by making it more relevant, but can also subtract value by distorting knowledge, possibly because their own perception of relevance may be misdirected.

\section{The labyrinth of contextualisation}

The literature on post-communist emerging markets reports numerous instances of scepticism towards the applicability and relevance of Western business theory on the part of the local business community, tutors and students (Branine 2005; Holden 2002; Hollinshead 2006; Hollinshead \& Michailova 2001; Kuznetsov et al. 2009; Vaiman \& Holden 2013). This is often a reflection of a general cautious attitude to Western values in the society. In Russia, for example, public opinion polls reveal that a substantial proportion of the citizens consistently expresses preference for an economic system based on government planning and distribution over the market. According to Levada Centre, a leading Russian independent polling and sociological research organisation, over the period between 1997 and 2013, on average only 29\% of respondents accepted that the system based on private property and market relations was superior; approximately $20 \%$ believed that there was a discrepancy between the values and traditions of Russia and the West, whilst the number of respondents who wanted to see Russia in the future to be a "socialist state like the USSR" increased from 15\% in 1999 to 24\% in 2013 (Russian Public Opinion 2013:20). These data suggest that the environment for absorbing market 
knowledge in post-communist countries remains challenging, as the immediate relevance of Western knowledge is still being tested.

\section{Creating the realm of understanding}

As far as indigenous academics are concerned, in cases when they demonstrate scepticism towards Western business theorising, an important question is if this is an assessment of the objective business environment in the recipient countries as they recognise it, or a consequence of subjective limitations reflecting lack of awareness and understanding of imported concepts. Important conceptual cues that may help providing an answer to this question can be found in the theory of knowledge transfer as translation (for summary see Røvik 2016), sensemaking theory (Weick 1995) and the theory of intuitive choice (Kahneman \& Tversky 1973; Tversky \& Kahneman 1986; Gilovich et al. 2002). These theories throw light on different aspects of the issue of recontextualisation as an important element of knowledge absorption. When management knowledge is transferred from developed market economies to emerging markets, it does not just travel from one geographical location to another. In the emerging markets institutional transformations are not yet compete, which implies that the social value of some imported expertise, even of technical nature, may not be immediately recognisable. Despite this, educators are tasked to spread and popularise this expertise to support and foster institutional reforms as a response to the opening up of formerly closed or semi-closed economies to the processes of globalisation. 
Literature is quite unanimous in emphasizing the role of common social awareness and conventions, sometimes called "the realm of understanding," in establishing the relevance of knowledge and thus facilitating the knowledge accession and absorption processes (see, for example, Papoutsakis \& Vallès 2003). As follows from knowledge transfer as translation theory, the first act of knowledge transfer is decontextualisation, i.e. translating a context-specific body of knowledge into an abstract representation (e.g., images, words and texts) (Røvik 2016). The receiver obtains therefore not the original ideas but their encoded symbols that has to be turned back into ideas through decoding. This has the potential to create distortions if there is a mismatch between encoding and decoding as, for example, different meanings can be attributed to the same words. The presence of common experience provides a "feeling for context", where context is defined as implied assumptions, that is essential to overcome the challenge of the embeddedness of knowledge and avoid or minimize the distortion of communication (Child 2000; Eco 2003).

\section{The textual aspect of conceptualisation}

Sensemaking theory offers two important insights pertinent to the topic in hand. One is that sensemaking is retrospective and social because it is rooted in accumulated experience and professional culture (Weick et al. 2005). What follows is that an abrupt change in the social environment discounts the value of the existing institutions, knowledge and expertise to the extent of making them redundant and thus removes salient clues enabling sensemaking. The other insight is that sensemaking is an issue of language, talk, and communication; that because of sensemaking "situations, organizations, and environments are talked into existence" (Weick et al. 2005: p.409). From this perspective, making sense is a textual 
process. As Robichaud et al. (2004: p.619) sum up, "sensemaking, to the extent that its object is the representation of human action and interaction, is based in narrative". Much of the reality, of which sense is to be made, presents itself not as something sensual, but as a collection of written and oral texts and derived imaginary.

This observation is important because it draws attention to the role of professional language in creating the realm of common understanding required for contextualisation. As Booker et al (2008) point out, in the West the existence of a proprietary language has become the hallmark of a well-developed academic discipline. Academics often speak in a specialised language that outsiders to the discipline may find exclusive and inaccessible. Business and management is one such field of study that increasingly employs a specially developed jargon to convey very particular ideas (Doupnik \& Richter 2003). A prominent feature of professional discourse in business is that it is inherently idiosyncratic: the understanding of professional terms depends on other professional terms in a lengthy circular series of iterations (Chisholme \& Milne 2013). The development of new business concepts, argue Chisholme and Milne (2013), often is more akin to inventions (contrived creations) rather than discoveries of facts. As a result, the explicitness of knowledge suffers as terms related to such concepts reflect the circumstances of their application and less the objective reality. This creates a sequence that makes the mediation of knowledge relevance even more problematic: lack of common social awareness deters the absorption of imported expertise, which in turn prevents the expansion of the field of collective experience as a factor making this expertise relevant and sought after. 
There is, therefore, a risk of ambiguity even if the sender and the receiver of information share the language and general culture, but do not belong to the same professional subculture. Such risk grows as the incoming messages become more specialised as a consequence of the professionalisation of discourse, thus narrowing even further the field of useful common experience. In the case of international knowledge exchange of the kind that exists between Western academics and their colleagues in the transition economies, things become even more complicated: semantic distortions multiply following the need to translate messages from one language into another while socio-cultural diversity amplifies chances of misunderstanding ${ }^{3}$. Furthermore, translated texts, lecture materials, educational programmes, case studies, etc., represent the "captured" elements of knowledge. But knowledge has aspects that cannot be easily codified, captured and stored. This tacit knowledge (Nonaka 1991) consists of mental models, beliefs and perspectives so ingrained that people cannot easily articulate them. Tacit knowledge is even more context embedded than codified knowledge; it is not an inherent property of the human being, but a product of social experience, education and other similar causes. The common field of experience therefore is important not only in order to preserve the meaning of communication but also to competently appreciate knowledge relevance and social value in their totality.

\section{The tutor as knowledge gatekeeper}

We propose that the performance of indigenous tutors as knowledge gatekeepers (mediators) will depend on their evaluation of the revealed relevance of the message they are passing on: if they see it as irrelevant this will negatively affect their effort. At the same time, their ability to evaluate relevance is related to how receptive they are to knowledge 
that they transmit. Their receptivity, in turn, depends on a combination of factors that include both subjective elements related to the intellectual aptitude of individual academics (e.g., ability to think critically, creative problem solving, memory, etc.) and certain objective characteristics representing the environment in which they operate.

In emerging economies these characteristics acquire particular importance considering the lack of experience of the modern market relations. A knowledge inflow has been seen as a means of catching up through replicating expertise available in advanced market economies. Replication requires that incoming knowledge is reproduced as accurately as possible with minimum distortions. For indigenous educators in the recipient countries this converts into a number of functional issues. A fundamental one, obviously, is the need to comprehend the message in its entirety before they pass it on to their students. This requires a "feeling for context" that, in the emerging markets, however, may not be yet fully supported by an actual social experience. This is not the only challenge.

The role of the tutor as a gatekeeper for imported knowledge has an internal conflict. As a medium in a communication process, ideally the tutor should be neutral towards the content of the message, focusing on guaranteeing the accuracy of relay from the sender to the receiver. At the same time, the teacher is expected to provide those elements of social experience that instils imported information with meaning by interpreting it in reference to a particular paradigm (Marakas 1999) and thus transforming information into knowledge. This may be achieved either by presenting to the audience a mental model of the context in which knowledge was created originally or by reconceptualising knowledge to make it 
more relevant to the actual context in the recipient country. The first option may help maintaining the integrity of knowledge, but at the cost of undermining its relevance because knowledge is still presented in reference to a context of which the recipients have no firsthand experience. The second option puts the tutor on the path of "creative destruction" of knowledge when relevance is enhanced through the rethinking and, hence, inevitably some degree of distortion of the original concept-message. Rethinking is necessary to create associative links that anchor the message within the cognitive space of the recipient audience. Although research on innovation diffusion (for overview see De Corte 2003) holds the view that the divergence and lack of shared experiences are actually beneficial for developing new ideas, when the objective is knowledge reuse, "creative destruction" becomes a very delicate balancing act. Without the backing provided by inspired interpretation that puts imported concepts in the context of local realities business knowledge transfer is more likely to remain a formality than become a powerful tool of changing existing practices as, deprived of context, knowledge cannot fully reveal its social relevance.

The material gathered from questionnaire-based surveys of academics in two ex-Soviet republics, Belarus and Kyrgyzstan, provide us with vivid and representative illustrations of the conceptual points discussed in the paper.

\section{Knowledge gatekeeping in emerging markets}

The surveys took place in 2003-2004 as the two countries marked the completion of the first decade of post-communist transition characterised by seismic shifts in almost all areas 
of social and economic life and probed, therefore, the reaction of the respondents to a radical change in the knowledge paradigm. The surveys made it possible to establish the qualitative profile of the university faculty teaching business related subjects and assess their preparedness and ability to act as gatekeepers of imported business knowledge.

Positioned in Europe and Asia respectively, Belarus and Kyrgyzstan are not only distant geographically but in many respects are also different in terms of culture, history, economic development and social conditions. Belarus has a well-developed industry and relatively high living standards; Kyrgyzstan is one of the poorest former Soviet republics with a predominantly agricultural economy. In the 1990s Kyrgyzstan attempted extensive market reforms; adhesion to the principles of free trade made Kyrgyzstan the first former Soviet republic to be accepted in the WTO. Liberal economic policies did not prevent a severe decline in production, resulting in the drop of per capita income by over $50 \%$. Although some recovery was achieved after 2003, the economy is heavily dependent on work migrants who contribute an estimated quarter of national GDP. Belarus was one of the most developed parts of the USSR. The country started market reforms in 1991, but their pace remained slow as the government reintroduced many of administrative controls and expanded intervention in the management of private enterprises. Nonetheless, after the initial contraction, the economy has been growing and the country managed to preserve its industrial base.

At the time of the surveys there were 57 state and private universities in Belarus and 49 in Kyrgyzstan. In contrast to quantitative sampling techniques that rely on statistical 
probability theory, our sampling was based on purposeful sampling principles. The aim was to identify "information-rich" participants who had direct experience relevant to the phenomenon of interest (Curry et al. 2009). In Belarus questionnaires were sent to all 628 full-time academic staff of all economic faculties and faculties of business and management of the state universities in the country. The response rate was $43 \%$. In Kyrgyzstan we surveyed 115 members of staff of the business departments of two most prominent institutions of higher education, the International University of Kyrgyzstan and Bishkek Academy of Finance and Economy and received 44 valid anonymous responses (38\% response rate). The questionnaire included 26 questions split into four sections: general information about the faculty; use of foreign literature and other sources; involvement in the process of international knowledge transfer; perceived barriers to international knowledge transfer. The questionnaire was a combination of closed and scale questions designed to reveal the attitude, characteristics and role of the academic staff involved in knowledge transfer.

\section{The picture of ambivalent success}

The results of the surveys provide an illustration of a situation in which radical changes in the knowledge paradigm put a non-trivial stress on knowledge gatekeepers. By the time of the surveys the two countries had behind them a decade of pro-market reforms and Western expertise had firmly established itself as a source of academic knowledge and educational materials, mostly in the form of translated and original texts, technical assistance and exchange programmes. Despite this, on average, a third of respondents strongly believed that the findings of Western theory were not relevant and another third gave this statement 
some support. These results echo findings by other researchers who reported scepticism towards the relevance (applicability) of Western business theory on the part of local tutors in other emerging economies (see, for example, Hollinshead \& Michailova (2001) on Bulgaria; Branine (2005) on China; Ursic \& Mulej (2005) on Slovenia). This scepticism could indeed be caused by some profound incompatibility of the situation in the source and the recipient countries. However, we were more interested in establishing if the subjective attitude of the academics was a factor.

\section{Competence and perceived relevance}

Our interpretation of these data is based on the understanding that the relevance in question is not an absolute category. Instead, individual educators enjoy some discretion, making it perceived or individualized relevance (Kobrynowicz \& Biernat 1997). In other words, knowledge itself is just one of a number of factors that influence the subjective perception of the validity of knowledge. We chose to investigate two aspects of the perceived relevance. One was the tutor's awareness and understanding of imported concepts. The other was the tutor's awareness and understanding of the local reality and its demands. We found that a substantial part of the respondents completed their higher education in the post-communist era. The majority reported proficiency in English; through technical aid programmes and scholars exchange quite a few of them were able to gain first-hand experience of Western educational principles and course content. At the same time, at least a third of the tutors, including the greater part of senior teaching staff, received their degrees in the pre-reform time. Despite this, the level of enmity towards Western ideas was low: only about $10 \%$ of respondents revealed any sort of resistance or contempt to imported 
knowledge. This is an interesting finding because it suggests that the "not-invented-here" syndrome, which is sometimes characterised in the literature as the most frequently mentioned bias influencing individual decision making when absorbing external knowledge for innovation (Antons \& Piller 2015), apparently was not a strong factor shaping the attitude of the academics.

This evidence suggests that the surveyed business and management faculty possessed many qualities allowing them to appreciate the value of imported concepts. What was lacking though was exposure to means that could allow to get the feeling of the context. Although the majority of respondents claimed good working knowledge of foreign languages (English, German, French), only a few declared regular use of original international scholarly and professional literature sources and, more importantly, regular consultation with foreign colleagues on professional topics. Many mentioned difficulties with understanding foreign business texts because of the terms and the particular style used, lacunas in own professional education and terminological confusions.

Even though the majority of tutors worked exclusively with translated sources, this did not remove all the semantic barriers. The teaching was done mostly in Russian, but it was apparent that the existing native lexis had difficulty handling modern management knowhow. The dismantling of central planning did not just put an end to a particular economic system; it also made obsolete the core knowledge and much of the professional language that were servicing this system. Some professional terms (e.g., controlling, benchmarking, outsourcing, marketing, recruiting, knowledge management) had no equivalents in Russian 
because there were no practical use for them under central planning. In the Russian editions of Western textbooks they were either transliterated or replaced with terms that the interpreters believed could have the same meaning, sometimes resulting in a confusing variety of expressions. Added to only limited experience with the markets, the deficiency of the vocabulary created a further barrier to the socialisation of Western knowledge.

Importantly, the scrutiny of evidence reveals that indigenous academics were struggling not only with imported concepts, but with making sense of the economic realities in their own countries as well. A third of respondents in Belarus had had no work experience outside the university sector and only $27.5 \%$ ever worked for private firms. At the same time there was the obvious deficiency of authoritative indigenous research. Four fifths of respondents believed that research by local authors did not have enough substance and conceptual weight to inform teaching on the national economy. By contrast, mass media was found to play a disproportionate role as a supplier of information used by academics for scholarly and teaching purposes. That academic faculty were inclined to ignore indigenous scholarly research as a useful resource providing systematic insight into local business issues is significant. This suggests that their understanding of "economic realities" at the time of the surveys was more intuitive than analytical, which raises a question about the validity of the criteria influencing their evaluation of the perceived relevance of Western knowledge. 


\section{Concluding remarks}

We have used an example of international knowledge transfer between developed and emerging markets to highlight the relative nature of the relevance of knowledge and the consequences this may have for knowledge exchange and adoption. One important constraint analysed in the paper is represented by the consequences of the contextual incongruity that restricts the ability of knowledge gatekeepers to rely on own embedded competencies and those of their audience as they transform incoming information into knowledge. As a result, what is accepted as "revealed" relevance in one socio-economic environment may appear to be of only "potential" relevance in a different environment. This is a serious stumbling block in the path of the adoption of new knowledge because, as Alvesson (2013) aptly points out, a low-relevance knowledge cannot be effectively absorbed by a society. Conversely, it may be argued that the knowledge that cannot be absorbed is not relevant.

We present relevance as a non-static, changing parameter. Revealing the relevance of external knowledge involves various enablers, such as institutions, interaction, communication, practices, experience, etc. Our analysis reveals that relevance is relative and subjective and the competence and worldview of the gatekeeper are critical for relevance discovery. In our analysis we focused on tutors working in universities as mediators of knowledge transfer, but there is no reason to believe that the basics of relevance discovery in other types of organisations is different. Commonly research assumes the neutrality of mediators. Latour (1996: p.304), for example, defines a mediator as "an event which is neither completely a cause nor a consequence". Instead, we 
concentrated on the circumstances under which this neutrality is challenged because social institutions go through a transition stage and cannot provide a solid foundation even for a "low-context" theorising. Lack of common experience with respect to old and new knowledge removes salient clues enabling sensemaking. The problem here is similar to the one identified by the literature on knowledge absorption by organisation: despite modern communication techniques, the flow of knowledge is hampered because the tacit elements of knowledge cannot be articulated and shared by means of codification (Hildreth \& Kimble 2002). The comprehension of sophisticated concepts relies upon ability to put tangible information into a contextual framework of which it was originally a part. In the absence of a common field of experience the validation of imported social knowledge by the recipient is, in a sense, an act of faith because some evidence that confirms its relevance cannot be reproduced locally. The recipients, eventually, have to develop own tacit knowledge which means becoming immersed in a similar experience, but this requires transformation of the socio-economic environment first. This implies that, under such circumstances, establishing the relevance of imported knowledge is necessarily a prolonged process that takes more time than is needed to introduce the formal attributes of a new knowledge paradigm (course content, textbooks, professional literature, etc.). To an extent, the challenge of recontextualisation may be mitigated if relevance discovery becomes an interactive process involving knowledge gatekeepers in recipient organisations and the senders of knowledge. The recipients may provide information that will allow the senders to arrange their message in a way that will simplify its recontextualisation. This may be achieved, for example, through personal mobility of knowledge workers and social networking. The development of tacit knowledge, as emphasised by Nonaka (1991), takes 
place through joint activities and has a need of physical proximity. At the same time, the social task of knowledge contextualisation requires that knowledge gatekeepers maintain a firm contact with the realities in their own countries.

The prominence of contextualisation as an enabler of relevance has been discussed to considerable extent in information science (e.g., Saracevic 2007) and linguistics (e.g., Wilson \& Sperber 2004), but less so in organisation and management sciences. It has established itself very strongly as an outcome of our study. We conclude that the impact of new knowledge on management practices may be significantly affected by the ability of knowledge gatekeepers to reconcile this knowledge with the objective reality and embedded theoretical beliefs. This is why critical thinking and critical reflective practices, which may be re-enforced through participation in professional and cross-sectoral networks, are so important to knowledge gatekeepers. They are necessary to free them from habitual ways of thinking.

Clearly, difficulties with absorbing imported knowledge are not just a feature of emerging economies. To a varying degree, they are likely to accompany any act of international knowledge transfer. We focused our analysis on the domain of management and business theorising, but the issues that we discussed have wider application. One practical implication of our analysis is the demonstration of the boundaries of expertise in situations in which superficial similarity may disguise substantial discrepancy, calling for willingness to question existing assumptions in both business and learning. Another practical implication follows from the emphasis that our analysis places on interactivity as an 
element of knowledge transfer. The recognition that radical knowledge creation is usually an interactive process has been around for some time (Bathelt et al. 2004). We demonstrate that under certain circumstances the contextualisation of imported knowledge following knowledge transfer has some characteristic of knowledge creation and therefore benefit from interaction between experts in source and recipient countries.

The juxtaposition of contextualisation of knowledge and creation of knowledge with reference to the social value of knowledge presents itself as a fruitful area for future research. In particular, the notion of "creative destruction" of imported knowledge when relevance is enhanced through rethinking may encourage further discussion on the role of knowledge gatekeepers in organisations.

\section{References}

ALLEN, T. J. (1977). Managing the flow of technology. Cambridge, MA: MIT Press.

ALVESSON, M. 2013. Do we have something to say? From re-search to roi-search and back again. Organization, 20(1), 79-90.

ASMUSSEN, C. G., FOSS, N. J. AND PEDERSEN, T. 2013. Knowledge transfer and accommodation effects in multinational corporations: Evidence from European subsidiaries. Journal of Management, 39(6), 1397-1429.

ANTONS, D. AND PILLERS, T. 2015. Opening the black box of "not invented here": Attitudes, decision biases, and behavioural consequences. Academy of Management Perspectives, 29(2), 193-217. 
ARGOTE, L. AND INGRAM, P. 2000. Knowledge transfer: A basis for competitive advantage in firms. Organizational Behavior and Human Decision Processes, 82(1), 150169.

BATHELT, H., MALMBERG, A. AND MASKELL, P. 2004. Clusters and knowledge: local buzz, global pipelines and the process of knowledge creation. Progress in Human Geography, 28(1), 31-56.

BLAIR, J. D. AND HUNT, J. G. 1986. Getting inside the head of the management researcher one more time: Context-free and context-specific orientations in research. Journal of Management, 12(2), 147-166.

BOOKER, L.D., BONTIS, N. AND SERENKO, A. 2008. The relevance of knowledge management and intellectual capital research. Knowledge and Process Management, 15(4), $235-246$.

BRANINE, M. 2005. Cross-cultural training of managers: An evaluation of a management development programme for Chinese managers. The Journal of Management Development, 24(5/6), 459-472.

CHANG, Y, Y., GONG, Y. AND PENG, M. W. 2012. Expatriate knowledge transfer, subsidiary absorptive capacity, and subsidiary performance. Academy of Management Journal, 55(4), 927-948.

CHILD, J. 2000. Theorizing about organization cross-nationally. In: Cheng JL \& Peterson RB (eds). Advances in International Comparative Management, Vol. 13 (pp. 27-76). Stamford CT: JAI Press. 
CHISHOLME, M. AND MILNE, A. 2013. The prospects for common financial language in wholesale financial services. SWIFT Institute Working Paper 2012-005. La Hulpe (Belgium): The SWIFT Institute.

COHEN, W. AND LEVINTHAL, D. 1994. Fortune favors the prepared firm. Management Science, 40(2), 128-52.

DE CORTE, E. 2003. Transfer as the productive use of acquired knowledge, skills, and motivations. Current Directions in Psychological Science, 12(4), 142-146.

DOUPNIK, T. S. AND RICHTER, M. 2003. Interpretation of uncertainty expressions: a cross-national study. Accounting, Organizations and Society, 28(1), 15-35.

ECO, U. 2003. Mouse or Rat? Translation as Negotiation. London: Weidenfeld \& Nicolson.

GILOVICH T., GRIFFIN, D. AND KAHNEMAN, D. 2002. Heuristics and Biases: The Psychology of Intuitive Judgement. Cambridge: Cambridge University Press.

GRIFFIN, E. 2003. A First Look at Communication Theory with Conversations with Communication Theorists 5th Ed. New York: McGrow-Hill.

GUILHON, B. 2001. The working of markets for knowledge. In B. Guilhon (Ed.) Technology and Markets for Knowledge. Knowledge Creation, Diffusion and Exchange within a Growing Economy (pp. 41-68). Dordrecht: Kluwer Academic Publisher.

HARORIMANA, D., 2008. Understanding the Role of Knowledge Gatekeepers in Knowledge Identification, Translation and Transfer Process: Some Empirical Evidences. In Proceedings of the 9th European Conference on Knowledge Management: ECKM2008 (p. 275). Academic Conferences Limited. 
HERZOG, A.J., 1981. The 'gatekeeper' hypothesis and the international transfer of scientific knowledge. The Journal of Technology Transfer, 6(1), 57-72.

HILDRETH, P. AND KIMBLE, C. 2002. The duality of knowledge. Information Research 8(1). Available at: http://informationr.net/ir/8-1/paper142.html (accessed 3 Nov 2015).

HOLDEN, N. 2002. Cross-cultural Management: A Knowledge Management Perspective. London: FT/Prentice Hall, Pearson Education.

HOLDEN, N., KUZNETSOVA, O. AND FINK, G. 2008. Russia's long struggle with Western terms of management and the concepts behind them. In S. Tietze (Ed), International management and language (pp. 114-127). London: Routledge.

HOLLINSHEAD, G. 2006. Educating educators in a volatile climate - The challenge of modernising higher business schools in Serbia and Montenegro. European Journal of Education, 41(1), 131-149.

HOLLINSHEAD, G. AND MICHAILOVA, S. 2001. Blockbusters or bridge-builders? The role of Western trainers in developing new entrepreneurialism in Eastern Europe. Management Learning, 32(4), 419-436.

KAHNEMAN, D. AND TVERSKY, A. 1973. On the Psychology of Prediction. Psychological Review, 80(4), 237-51.

KOBRYNOWICZ, D. AND BIERNAT, M. 1997. Decoding subjective evaluations: How stereotypes provide shifting standards. Journal of Experimental Social Psychology, 33(6), $579-601$. 
KUZNETSOV, A., KUZNETSOVA, O. AND WARREN, R. 2009. CSR and the legitimacy of business in transition economies: The case of Russia. Scandinavian Journal of Management, 25(1), 37-45.

LATOUR, B. 1996. Social theory and the study of computerized work sites. In: W. J. Orlinokowski \& G. Walsham (Eds.) Information Technology and Changes in Organizational Work (pp. 295-307). London: Chapman and Hall.

LEHRER, K. 1990. Theory of knowledge. London: Routledge.

LEVADA-CENTER. 2013. Russian Public Opinion. Moscow: Levada-Center. Available at: http://www.levada.ru/sites/default/files/2012_eng.pdf (accessed 3 November 2015).

LEWIN, A. Y., MASSINI, S. AND PEETERS, C. 2011. Microfoundations of internal and external absorptive capacity routines. Organization Science, 22(1), 81-98.

MACDONALD, S. AND WILLIAMS, C. 1993. Beyond the boundary: an information perspective on the role of the gatekeeper in the organization. Journal of Product Innovation Management, 10(5), 417-427.

MARAKAS, G. M. 1999. Decision support systems in the twenty-first century. Eaglewood Cliff, NJ: Prentice Hall.

MCCARTHY, D. J. AND PUFFER, S. M. 2003. Corporate governance in Russia: A framework for analysis. Journal of World Business, 38(4), 397-415.

MAY, R. C., PUFFER, S. M. AND MCCARTHY, D. J. 2005. Transferring management knowledge to Russia: A culturally based approach. Academy of Management Executive, 19(2), 24-35. 
MICHAILOVA, S. AND HUSTED, K. 2003. Knowledge-sharing hostility in Russian firms. California Management Review, 45(3), 59-77.

MORRISON, A., 2004. Gatekeepers of knowledge within industrial districts: who they are, how they interact. Università commerciale Luigi Bocconi.

NONAKA, I. 1991. The knowledge creating company. Harvard Business Review, 69 (Nov-Dec), 96-104.

PANDZA, K. AND THORPE, R. 2009. Creative search and strategic sense- making: missing dimensions in the concept of dynamic capabilities. British Journal of Management, 20(s1), S118-S131.

PAPOUTSAKIS, H. AND VALLÈS, R. S. 2003. Towards a taxonomy of knowledge, intellectual capital and their management based on information technology. SOCOTE, Valencia. Available at: http://grupos.unican.es/igestion/socote/pdf/ActasCongreso1.pdf\#page=175, (accessed 22 June 2015).

PHELPS, C., HEIDL, R. AND WADHWA, A. 2012. Knowledge, networks, and knowledge networks a review and research agenda. Journal of Management, 38(4), $1115-$ 1166.

RAELIN, J. A. 2009. The practice turn-away: Forty years of spoon-feeding in management education. Management Learning, 40(4), 401-410.

RØVIK, K.A. 2016. Knowledge transfer as translation: Review and elements of an instrumental theory. International Journal of Management Reviews, early view article, DOI: 10.1111/ijmr.12097. 
ROBICHAUD, D., GIROUX, H. AND TAYLOR, J. R. 2004. The metaconversation: The recursive property of language as a key to organizing. Academy of Management Review, 29(4), 617-634.

SARACEVIC, T. 2007. Relevance: A review of the literature and a framework for thinking on the notion in information science. Part III: Behavior and effects of relevance. Journal of the American Society for Information Science and Technology, 58(13), 2126-2144.

SCHULZ, M. 2001. The uncertain relevance of newness: Organizational learning and knowledge flows. Academy of Management Journal, 44(4), 661-681.

SCHULZ, M. 2003. Pathways of relevance: Exploring inflows of knowledge into subunits of multinational corporations. Organization Science, 14(4), 440-459.

TSUI, A. S. 2004. Contributing to global management knowledge: A case for high quality indigenous research. Asia Pacific Journal of Management, 21(4), 491-513.

TUSHMAN M. AND KATZ, R. 1980. External communication and project performance: An investigation into the role of gatekeepers. Management Science, 26(11), 1071-85. TVERSKY, A. AND KAHNEMAN, D. 1986. Rational Choice and Framing of Decisions. Journal of Business, 59(4), 252-278.

URSIC, D. AND MULEJ, M. 2005. Theory and practice of management concepts: Slovenia's Experiences. The Journal of Management Development, 24(10), 856-878.

VINDING, A. L. 2006. Absorptive capacity and innovative performance: a human capital approach. Economics of Innovation and New Technology, 15(4/5), 507-517.

VERCUEIL, J. 2012. Les pays émergents. Brésil - Russie - Inde - Chine...Mutations économiques et nouveaux défis. Paris: Bréal, 3rd Edition. 
VAIMAN, V. AND HOLDEN, N. 2013. Talent management in Russia: Not so much war

for talent as wariness of talent. Critical Perspectives on International Business, 9(1/2),

$129-146$.

WEICK, K. E. 1995. Sensemaking in Organizations (Foundations for Organizational

Science). Thousand Oaks: Sage Publications Inc.

WEICK, K. E., SUTCLIFFE, K. M. AND OBSTFELD, D. 2005. Organizing and the process of sensemaking. Organization Science, 16(4), 409-421.

WILSON, D. AND SPERBER, D. 2004. Relevance theory. In L. Horn \& G. Ward (Eds.), Handbook of pragmatics (pp. 607- 632). Oxford: Blackwell.

\footnotetext{
${ }^{1}$ There is a massive literature contrasting the central planning model with Western style management. Probably the most important books in English are Kornai. J. 1980. Economics of Shortage. Amsterdam: North-Holland; Nove, A. 1991. The Economics of Feasible Socialism Revisited. London: Harper Collins Academic; Ellman, M. 1989. Central Planning. Cambridge: Cambridge UP.

${ }^{2}$ There is no official list of emerging markets, different agencies and experts may disagree on its exact composition (see, for example, Financial Times Lexicon on http://lexicon.ft.com/Term?term=emergingmarkets). Most commonly, this term is applied to Russia and the other former Soviet republics, China, India, Brazil, and Colombia, Indonesia, Vietnam, Egypt, Turkey, South Africa, Bangladesh, Egypt, Indonesia, Iran, Korea, Mexico, Nigeria, Pakistan, the Philippines, Turkey and Vietnam.

${ }^{3}$ See Holden et al (2008) for the analysis of the misrepresentation of business terms in Russian translation.
} 